\title{
PRODUCCIÓN DE PROTEÍNA PARA NUTRICIÓN ANIMAL MEDIANTE BIOCONVERSIÓN DE SUSTRATOS AGROPECUARIOS
}

Diana María Cárdenas Caro Ingeniera de Producción Biotecnológica Calle 16N No.17E-73 Urb. Niza Teléfono: 5745502Celular: 3107658686

e-mail: dicarcaro@hotmail.com

Claudia Margarita Parada Puerto Ingeniera de Producción Biotecnológica Diag. 13E No.15N-66 Zulima 3 ${ }^{\text {a }}$ Etapa Teléfono: 5747618

Directora del Trabajo de Grado: Ing. Qca. Yaneth Muñoz

Asesora Microbiológica:

Dra. Laura Yolima Moreno

UNIVERSIDAD FRANCISCO DE PAULA SANTANDER

FACULTAD DE CIENCIAS AGRARIAS Y DEL AMBIENTE

PLAN DE ESTUDIOS DE INGENIERÍA DE PRODUCCIÓN BIOTECNOLÓGICA

FACULTAD DE CIENCIAS BÁSICAS

LABORATORIO DE MICROBIOLOGÍA

\section{RESUMEN}

Se realizó la selección de un microorganismo para la bioconversión aerobia en estado semisólido de un sustrato, con el propósito de producir proteína microbiana para la elaboración de un alimento concentrado para ganado bovino de doble propósito. El proceso se realizó con raíz de yuca y melaza como sustrato, adicionando nutrientes esenciales para el microorganismo. La temperatura utilizada osciló entre 28 y $32^{\circ} \mathrm{C}$, con un $\mathrm{pH}$ de 4,5 +/- 0,5, agitación y aireación constantes con valores específicos para cada etapa y escalamiento del estudio. Se desarroIlaron escalas de laboratorio y planta piloto, formulando además, la producción industrial a nivel de 2000 L. El sistema de lote utilizado en la obtención de preinóculos, inóculos y bioconversión, permitió obtener un alto porcentaje de proteína en base seca $(39,85 \%)$ a partir de subproductos agrícolas y agroindustriales que, actualmente contribuyen a la contaminación ambiental por residuos sólidos en regiones aledañas a San José de Cúcuta.

Palabras claves: Torula, Candida utilis, Saccharomyces cerevisiae.

\section{INTRODUCCIÓN}

En el sector agropecuario existe un gran listado de factores que influyen en la productividad, dentro de los cuales, el aprovechamiento de los recursos disponibles es indispensable para cualquier actividad relacionada con el gremio. Sin embargo, actualmente, los niveles de adopción de tecnología no son satisfactorios, debido en parte a los costos y a la escasez de los planes de transferencia de tecnología, de las entidades responsables de esta labor.

La deficiencia alimentaria de los animales, en cuanto a proteína se refiere, así como la contaminación por desechos agroindustriales en las zonas rurales, por la falta de educación y gestión ambiental, conlleva a que las nuevas tecnologías como la biotecnología, mediante la aplicación integrada de las técnicas de la Bioquímica, la Microbiología y la Ingeniería Química, aprovechen en el plano tecnológico las propiedades y posibilidades de los microorganismos y cultivos celulares para hacer un uso más eficiente y racional de los desechos y subproductos renovables.

Este trabajo permitió, utilizar algunos de estos recursos, como son la melaza azucarera y la raíz de yuca, proporcionándolos como sustrato alimenticio a microorganismos como las levaduras, para convertir-los en un producto enriquecido proteínicamente $\mathrm{y}$, posteriormente, ser llevado a formar parte de un concentrado para alimentación bovina de doble propósito, la cual ocupa en el Norte de Santander, el mayor porcentaje de explotación ganadera y permite reducir entre un 25 y $30 \%$ el costo de producción, si se tiene en cuenta que en muchos casos, la nutrición está representando hasta un $70 \%$ de éstos con lo que podría aumentarse significativamente las utilidades del productor.

Para esto se desarrolló un proceso biotecnológico, utilizando métodos alternativos, con el fin de obtener un producto competitivo en el mercado, ofreciendo una fuente no convencional de proteína para la nutrición animal, lo cual permite la introducción de nuevas técnicas en lo que se refiere a la producción pecuaria y la conservación ambiental, pues de alguna manera se disminuye la contaminación que genera la acumulación de estos recursos en las diferentes zonas del departamento.

\section{MATERIALES Y MÉTODOS}

Para la selección del microorganismo se utilizaron dos sustratos sólidos, yuca y cachaza de caña de azúcar, en diferentes porcentajes, 
suplementados con melaza (12 $13^{\circ}$ Brix) y los demás nutrientes requeridos por las células de levadura empleadas en los bioensayos. Se estudiaron cepas de Candida utilis (Cepa UCLV - CUBA) y Saccharomyces cerevisiae (comercial Fleischmann).

Se formularon dos medios líquidos de cultivo alternativo para el crecimiento del preinóculo e inóculo de la levadura seleccionada en los bioensayos descritos anteriormente, Candida utilis (Torula), teniendo en cuenta condiciones ambientales y de trabajo básicas, fácilmente controlables como temperatura, $\mathrm{pH}$, ${ }^{\circ} \mathrm{Brix}$, agitación (r.p.m.) y aireación (VVM).

El parámetro tomado como referencia para la selección fue el crecimiento celular por ml Vs. tiempo, analizado por conteo celular en cámara de Neubauer factor $5^{\star} 10^{4}$.

Se obtuvieron los volúmenes necesarios para la producción de suspensión celular, preinóculo e inóculo, teniendo en cuenta concentraciones celulares iniciales, empleando cultivos de alta densidad celular (100 $160 \mathrm{gr}$ de levadura en peso seco / litro de sustrato).

El proceso de bioconversión del sustrato semisólido se llevó a cabo en sistema por lote, utilizando un biorreactor de vidrio para escala de laboratorio (2 L). En esta etapa se analizó una variable crítica como la aireación, suministrada en valores de VVM (Volumen de aire / Volumen de medio / Minuto), teniendo en cuenta que la propagación masiva de células requiere un óptimo suministro de oxígeno.
La fase de laboratorio permitió el desarrollo de la escala piloto $(20 \mathrm{~L})$, en donde se diseñó y construyó un biorreactor en acero inoxidable con dispositivos para suministro de aireación, pasteurización "in situ", salida de gases, inoculación de células, toma de muestras y agitación mecánica. El escalamiento industrial se proyectó a nivel de 2000 $\mathrm{L}$, formulando el diseño de los biorreactores necesarios utilizando condiciones de escalamiento para la configuración geométrica estándar de equipos industriales.

El alimento concentrado para ganado bovino de doble propósito se formuló mediante un sistema de programación, teniendo en cuenta la composición bromatológica del sustrato enriquecido después de la bioconversión. Las materias primas necesarias para balancear los nutrientes requeridos por esta especie bovina, se adicionaron en su respectivo porcentaje hasta obtener una mezcla uniforme a la cual se le analizó su composición nutricional final y su carga microbiana según especificaciones del Instituto Colombiano Agropecuario, ICA.

\section{RESULTADOS Y DISCUSIONES}

El microorganismo seleccionado fue Candida utilis, por su mayor productividad en yuca : melaza, superando a Saccharomyces cerevisiae en los dos sustratos evaluados. (Cuadro 1 y Figura 1)

Se estableció un tiempo de producción del preinóculo de 3 horas, donde se alcanza una etapa exponencial para eliminar la fase estacionaria del inóculo que se realiza en un tiempo máximo de 6 horas, utilizando una suspensión celular de $160 \mathrm{gr}$ de levadura en peso seco / litro de sustrato.

Cuadro 1. Crecimiento celular de los bioensayos para yuca y cachaza de caña de azúcar con levadura Torula y Saccharomyces cerevisiae (cell / ml)

\begin{tabular}{|c|c|c|c|c|}
\hline \multirow{2}{*}{$\mathrm{T}$} & \multicolumn{2}{|c|}{$\begin{array}{c}\text { Yuca : Melaza } \\
\text { (cell / ml) }\end{array}$} & \multicolumn{2}{|c|}{$\begin{array}{c}\text { Cachaza : Melaza } \\
\text { (cell / ml) }\end{array}$} \\
\hline & $\begin{array}{c}\underline{S} . \\
\text { cerevisiae }\end{array}$ & Torula & $\begin{array}{c}\underline{S} . \\
\text { cerevisiae }\end{array}$ & Torula \\
\hline T0 & $2,6 * 10^{8}$ & $2,6^{*} 10^{8}$ & $2,0^{*} 10^{8}$ & $2,7^{*} 10^{8}$ \\
\hline $\mathrm{T} 1$ & $5,8^{*} 10^{8}$ & $1,1^{*} 10^{9}$ & $3,6^{*} 10^{8}$ & $8,4^{*} 10^{8}$ \\
\hline T2 & $5,4^{*} 10^{8}$ & $1,1^{*} 10^{9}$ & $2,6^{*} 10^{8}$ & $4,9^{*} 10^{8}$ \\
\hline T3 & $4,3^{*} 10^{8}$ & $1,2^{*} 10^{9}$ & $1,7^{*} 10^{8}$ & $2,6 * 10^{8}$ \\
\hline $\mathrm{T} 4$ & $4,7^{*} 10^{8}$ & $8,9^{*} 10^{8}$ & $3,0^{*} 10^{8}$ & $1,3^{*} 10^{8}$ \\
\hline T5 & $4,0^{*} 10^{8}$ & $8,6^{*} 10^{8}$ & $1,8^{*} 10^{8}$ & $1,8^{*} 10^{8}$ \\
\hline T6 & $4,8^{*} 10^{8}$ & $1,3^{*} 10^{9}$ & $8,9^{*} 10^{7}$ & $1,0^{*} 10^{7}$ \\
\hline $\mathrm{T} 7$ & $4,5^{*} 10^{8}$ & $1,3^{*} 10^{9}$ & $1,6^{*} 10^{7}$ & $2,2^{*} 10^{7}$ \\
\hline T8 & $4,3^{*} 10^{8}$ & $8,6^{*} 10^{8}$ & $1,0 * 10^{8}$ & $2,1^{*} 10^{7}$ \\
\hline T9 & $1,8^{*} 10^{8}$ & $7,4^{*} 10^{8}$ & $1,1 * 10^{7}$ & $2,1^{*} 10^{7}$ \\
\hline $\mathrm{T} 10$ & $2,2^{*} 10^{7}$ & $5,9^{*} 10^{8}$ & $3,5^{*} 10^{7}$ & $1,5^{*} 10^{7}$ \\
\hline
\end{tabular}


Desviación estándar $(\sigma)=1,1^{\star} 10^{8} \mathrm{cell} / \mathrm{ml}$

Fuente: Las autoras

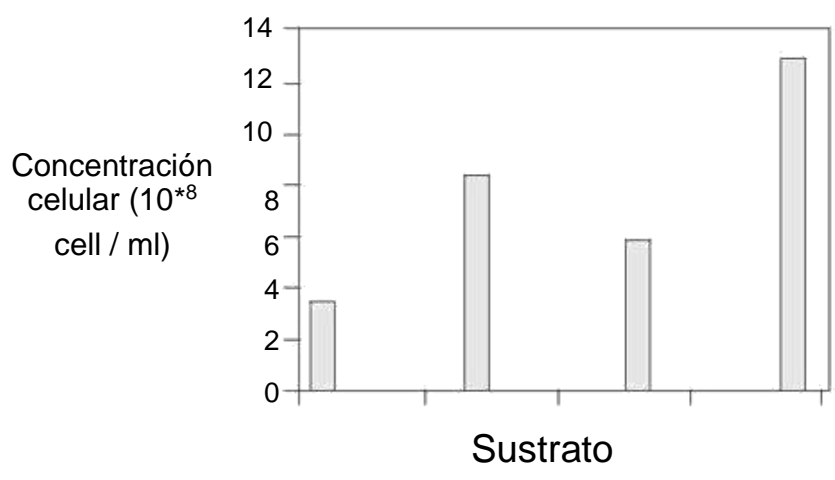

Cazacha de caña de azucar (S.c.)

Cazacha de caña de azucar (S.c.)

Raíz de yuca (C.u.)

Raíz de yuca (C.u.)

Figura 1. Crecimiento celular de S.c. y C. u. en sustratos semisólidos

El enriquecimiento protéico del sustrato semisólido se llevó a cabo en un tiempo de 12 horas, utilizando un valor de 9 VVM en la aireación, para obtener una concentración celular final de $23{ }^{*} 10^{9}$ cell / $\mathrm{ml}$ y un contenido de $39,85 \%$ de proteína bruta, analizado por el método colorimétrico de Biuret para proteína soluble en muestras húmedas.

La etapa de planta piloto (20 L) presentó resultados muy similares a los obtenidos en laboratorio ( $2 \mathrm{~L})$, pues los rangos de las variables controladas, fueron mantenidos estrictamente, teniendo en cuenta el escalamiento desarrollado. El montaje del biorreactor puede observarse en la Figura 1, con sus equipos anexos requeridos.

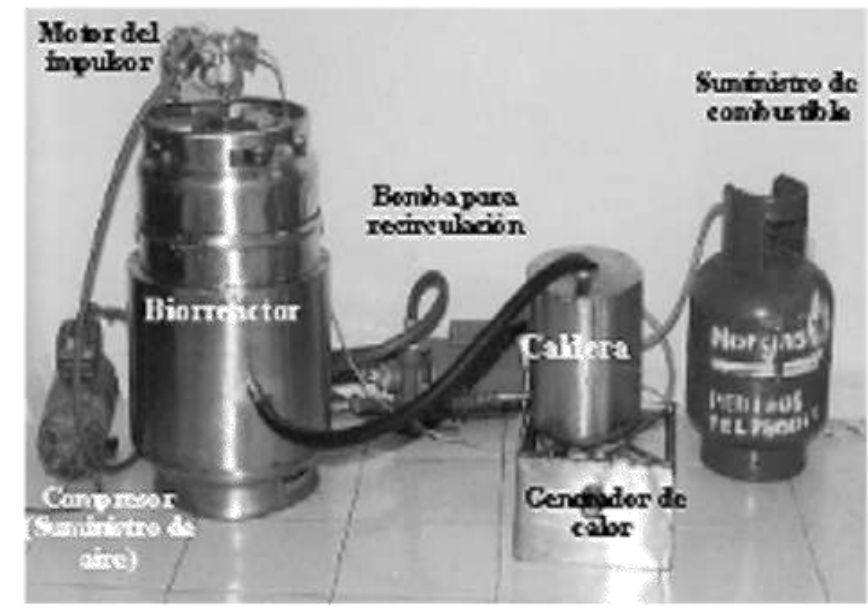

Figura 2. Biorreactor a escala piloto $(20 \mathrm{~L})$

Para formular el alimento, se seleccionaron materias primas de la región, de buena disponibilidad, teniendo en cuenta su composición bromatológica con el fin de balancear los nutrientes requeridos por el ganado bovino doble propósito. En la elaboración del alimento en el laboratorio, se utilizaron cuatro etapas fundamentales: secado y molienda del sustrato enriquecido con proteína unicelular, pesaje de las materias primas y mezclado para obtener un producto uniforme.

Los análisis bromatológicos y microbiológicos que se realizaron a la muestra del alimento concentrado producido en el laboratorio, fueron satisfactorios para los requisitos nutricionales del ganado bovino doble propósito permitiendo ofrecer al animal una dieta balanceada y ausente de microorganismos patógenos. (Cuadro 2).

Cuadro 2. Análisis bromatológicos y microbiológicos del alimento concentrado

\begin{tabular}{|c|c|c|c|c|}
\hline \multicolumn{3}{|c|}{ Bromatológicos* } & \multicolumn{2}{|c|}{ Microbiológicos** } \\
\hline \multirow{2}{*}{$\begin{array}{l}\text { Componente } \\
\text { Humedad }\end{array}$} & \multicolumn{2}{|c|}{ Valor Requerimiento } & Análisis & Valor \\
\hline & 10,89 & $\leq 20$ & $\begin{array}{l}\text { Aerobios } \\
\text { mesófilos }\end{array}$ & $\begin{array}{l}17^{*} 10^{2} \\
\text { ufc / gr }\end{array}$ \\
\hline $\begin{array}{l}\text { Proteína } \\
\text { bruta* }^{*}\end{array}$ & 16,46 & $15-17$ & $\begin{array}{l}\text { Hongos y } \\
\text { levaduras }\end{array}$ & $\begin{array}{l}90 * 10 \\
\text { ufc / gr }\end{array}$ \\
\hline Fibra cruda & 7,50 & $5-7$ & $\begin{array}{l}\text { Coliformes } \\
\text { totales }\end{array}$ & $\begin{array}{l}4 \text { bact. } \\
\text { NMP / gr }\end{array}$ \\
\hline $\begin{array}{l}\text { Extracto } \\
\text { etéreo }\end{array}$ & 5,84 & $5,5-7,5$ & $\begin{array}{l}\text { Coliformes } \\
\text { fecales }\end{array}$ & $\begin{array}{l}3 \text { bact. } \\
\text { NMP / gr }\end{array}$ \\
\hline $\begin{array}{l}\text { Extracto no } \\
\text { nitrogenado }\end{array}$ & 50,59 & $>40$ & $\frac{\text { Salmonella }}{\mathrm{sp} .}$ & $\begin{array}{l}\text { Ausencia } \\
\text { / } 25 \mathrm{gr}\end{array}$ \\
\hline Cenizas & 8,72 & $7-9$ & & \\
\hline
\end{tabular}




\section{CONCLUSIONES}

Según los resultados obtenidos en los bioensayos para la selección de sustrato y microorganismo, se obtuvo mayor crecimiento de células de Candida utilis con respecto a Saccharomyces cerevisiae en la composición de $70 \%$ de melaza en $1213^{\circ}$ Brix y $30 \%$ de raíz de yuca, siendo esta materia prima muy utilizada en procesos de fermentación por microorganismos, por las características nutricionales que presenta, especialmente en su alto contenido de azúcares.

En la formulación del medio de cultivo para la obtención del inóculo, se seleccionaron componentes de bajo costo y buena disponibilidad en la región, aprovechando subproductos del sector agroindustrial, que permitieron un óptimo crecimiento celular.

Se realizaron bioensayos en escala de laboratorio ( $2 \mathrm{~L}$ ) en donde se optimizaron los parámetros esenciales de la propagación celular, con lo que se pudo escalar a nivel piloto $(20 \mathrm{~L})$ verificando que al mantenerlos constantes se obtiene el mismo comportamiento celular. Esto permitió proyectar un escalamiento industrial (2000 L) para estimar los costos de producción.

Para el desarrollo de la escala piloto $(20$ L) se construyó un biorreactor en acero inoxidable que mantenía las condiciones geométricas y mecánicas del fermentador a escala de laboratorio ( $2 \mathrm{~L})$, como el suministro de aireación, salida de gases, sistema toma muestra, punto de inoculación y sistema de pasteurización "in situ", lo cual favoreció el proceso de preparación del sustrato semisólido en condiciones asépticas y permitió obtener resultados muy similares al volumen de $2 \mathrm{~L}$.

En la escala industrial además de los biorreactores se seleccionaron los equipos necesarios para la elaboración del alimento concentrado como son: la peladora lavadora de yuca, picadora tipo pica pastos con discos perforados, caldera, horno secador tipo bandeja, molino de martillo y mezcladora.

El costo de producción del alimento concentrado para ganado bovino de doble propósito con proteína unicelular resultó ser aproximadamente un 20\% más eco-nómico que algunos concentrados ofrecidos en el mercado que utilizan torta de soya para suplir este requerimiento, lo cual es importante para el sector ganadero si se tiene en cuenta su alta influencia en este tipo de explotación pecuaria.

Se formuló una alternativa para la reutilización de subproductos agrícolas y agroindustriales con el fin de reducir la contaminación ambiental por la frecuente generación de los mismos al entorno, estableciendo para esto un proceso biotecnológico para la obtención de proteína unicelular como materia prima principal de un concentrado alimenticio para ganado bovino de doble propósito.

El departamento Norte de Santander y su zona de frontera con Venezuela podrá ser una plaza proveedora de materia prima protéica de muy buena calidad para elaboración de alimentos concentrados para cualquier tipo de animales de producción.

\section{BIBLIOGRAFÍA}

BROCK, Thomas D. Biología de los microorganismos. Barcelona: Omega, 1985.

BUITRAGO H., Gustavo, et al. Construcción y puesta en marcha de un microfermentador. En: Ingeniería e investigación. Vol. 4, No. 2. (Trimestre 1 de 1987); p. 6067.

BUITRAGO, Julián A. La yuca en la alimentación animal. Publicación No. 85. Cali, Colombia: CIAT, 1998. p. 287294.

BU'LOCK J. Y KRISTIANSEN B. Biotecnología Básica. España: Acribia, 1.991. p. 285307.

CAICEDO L., et al. Estudio comparativo de cuatro sistemas de propagación de levadura cervecera por lote 
alimentado. En: Revista Colombiana de Biotecnología. p. 5156.

CENTRO INTERNACIONAL DE AGRICULTURA TROPICAL. Resúmenes analíticos sobre yuca (Manihot sculenta, Crantz). Vol. 15 No. 1/3. (Abr. Dic., 1989). Cali: CIAT, 1989. ISSN 0120-2898.

CONSTITUCIÓN POLÍTICA DE COLOMBIA. Décima tercera edición. Santafé de Bogotá, Colombia: Temis, 1998. 299 p.

CORPOICA. Análisis de los sistemas agropecuarios del departamento Norte de Santander. Documento de planificación territorial. Programa regional de sistemas de producción. Bucaramanga: Libertad, 1.997. 73 p.

COURSE NOTES. Isolation of protein \& Nucleic Acids. En: 2PAB-isolation of proteins \& Nuclei Acids (RCF).htm

CRUEGER, Wulf y CRUEGER, Anneliese. Biotecnología. Manual de microbiología industrial. Zaragoza, España: Acribia. p. 40 41, 67 71, 73123.

CHONA HERRERA, Ciro y GONZÁLEZ NIÑO, José Hernán. Inclusión de Cassapro en la dieta alimenticia de pollos de engorde. San José de Cúcuta, 1999. 136 p. Trabajo de grado (Tecnólogo Agropecuario). Universidad Francisco de Paula Santander. Facultad de Ciencias Agrarias y del Ambiente.

DORAN, Pauline M. y GARCÍA, Francisco J. Principios de ingeniería de los bioprocesos.

Zaragoza, Escpaña: Acribia, 1995. 468 p.

ENSMINGER, M.E. Producción bovina para carne. Centro regional de ayuda técnica para el desarrollo internacional. Buenos Aires, 1980. p. 172179.

ERTOLA, Rodolfo, et al. Microbiología industrial. Centro de investigación y desarrollo en fermentaciones industriales. La Plata, Argentina: Kingraf, 1994. 104 p.
ESCOBAR LÓPEZ, Jaime, et al. Levadura de cerveza ¿desaprovechada? En: Holstein Colombia. (Julio de 2000). p. 4243.

INSTITUTO COLOMBIANO AGROPECUARIO, ICA. Buenas prácticas en la fabricación de alimentos para animales en Colombia. Colombia: Produmedios, 1999. $28 \mathrm{p}$.

Ganadería de doble propósito. Memorias seminario internacional. Colombia: Produmedios, 1993. p. 3337.

Panorama de la ganadería de doble propósito en América Latina. Santafé de Bogotá, Colombia: ICA, 1989. p. 113191.

Pastos y forrajes para bovinos. Santafé de Bogotá, Colombia: ICA, 1990. p.35 - 39, 4951.

Reglamentación de los insumos pecuarios. Colombia: Produmedios, 1996. 42 p.

JAGNOW G. y DAWID W. Biotecnología. Introducción con experimentos modelos. Zaragoza, España: Acribia, 1.991. p. 5769 ,198 199.

JUERGENSON, Elwood M. y MORTENSON, W. P. Prácticas aprobadas en la producción de leche. México: Continental, 1980. p. 164171.

KUNZ, Benna. Cultivo de microorganismos para la producción de alimentos. Obtención, aplicaciones e investigación. Zaragoza, España: Acribia, 1986.

LATORRE RAMÍREZ, Sergio y MATEUS ECHEVERRÍA, Henry. Uso de subproductos agroindustriales en la alimentación de bovinos. Corpoica. p. 76.

FAO TROPICAL FEEDS. Levaduras y mohos. En:

MARÍN CÁRDENAS, Alfredo, et al. Producción de biomasa protéica a partir de jugo de caña. En: 
Respuestas. Año 4 . No. 1 (Mayo de 1999). p. 3234.

Mc.DONALD, P., et al. Nutrición animal. Quinta edición. Zaragoza, España: Acribia, 1995. 576 p.

MELGAREJO ANGARITA, Nelson Humberto y PIZZA RANGEL, Duván René. Proceso de enriquecimiento protéico de la yuca (Manihot sculenta) por fermentación en estado sólido (Cassapro) en condiciones rurales. San José de Cúcuta, 2000. Trabajo de grado (Tecnólogo Agropecuario). Universidad Francisco de Paula Santander. Facultad de Ciencias Agrarias y del Ambiente.

PELCZAR, Michael J., et al. Microbiología. Cuarta edición. México: McGraw-Hill, 1997. p. 271287.

PÉREZ DOMÍNGUEZ, Marcelo. Manual sobre ganado productor de leche. México: Diana, 1982. p. 89 93, 100 109, 213215.

SALAMANCA S., Rafael A. Pastos y forrajes. Producción y manejo. Santafé de Bogotá: Universidad Santo Tomás, 1990. p. 187 229, 243255.

SHAY, L. K. y WEGNER, G. H. Improved Fermentation Process for producing Torula Yeast. En: Food Technology. Octubre de 1985; p. 6166. VALIÑO, A. y MARIN, A. Abonos y concentrados. Colombia, 1999.

VALIÑO, A. y MARIN, A. Abonos y concentrados. Colombia, 1999.

WARD, Owen P. Biotecnología de la fermentación. Zaragoza, España: Acribia, 1.991. 
